\author{
Д. В. Аюшеева
}

\title{
СИСТЕМА ТУПКУ
}

В ЗАПАДНОЙ ТРАДИЦИИ ТИБЕТСКОГО БУДДИЗМА

На современном этапе развития тибетского буддизма на Западе стал укореняться институт тулку. Сложность внедрения данной модели в практику буддизма на Западе заключается в том, что западному адепту предстоит согласиться с тем, что его учитель, авторитетный тибетский лама, в своем следующем рождении может быть опознан в личности западного человека и в связи с этим возникнут проблемы взаимоотношений учеников с перерожденцем их духовного наставника. Выстраивание таких отношений представляется все более важным элементом в создании и поддержании целостности, требуемой для выживания и дальнейшего успешного развития тибетского буддизма на Западе.

Ключевые слова: тибетский буддизм, институт тулку, реинкарнация, западная культура.

\section{V. Ayusheeva}

\section{SYSTEM OF TULKU IN THE WESTERY TRADITION OF TIBETAY BUDDHISM}

At the present stage of the development of Tibetan Buddhism in the West the tulku institution began to take roots. The difficulty of introducing this model into the practice of Buddhism in the West is that the Western adept should agree that his teacher the authoritative Tibetan lama in his next birth can be identified in the person of a Western man and in this regard, there will be problems of the relationship of students with the reincarnation of their spiritual teacher. The building of such relations is an increasingly important element in creating and maintaining the integrity required for the survival and further successful development of Tibetan Buddhism in the West.

Keywords: Tibetan Buddhism, Tulku Institute, reincarnation, Western culture.

На современном этапе развития тибетского буддизма на Западе институт тулку, обеспечивающий непрерывность и целостность линии преемственности, укрепляется в западных странах. Речь идет об особом статусе духовных лиц, называемых тулку (перерожденцами), присутствие которых в тибетской традиции является ее основной характеристикой. Тщательно разработанная система,

Аюшеева Дулма Владимировна - кандидат философских наук, старший научный сотрудник Федерального государственного бюджетного учреждения науки «Институт монголоведения, буддологии и тибетологии СО РАН» (г. Улан-Удэ, Россия). E-mail: dulmaayush@yandex.ru. 
включающая в себя предсказания как предшествующих лам, так и тех, кто выбран для поисков их новой реинкарнации, легитимирует статус тулку.

Признание тулку в Тибете, Индии, Непале - обычное явление, но в последние 10 лет институт тулку начал укореняться и на Западе: тибетские ламы стали признавать реинкарнации представителей линии преемственности не только среди тибетцев, но и западных людей. Так, американка Катарина Бугс [Amy Lavine 1998: 105] известна под именем Акон Лхамо и официально признана перерождением йогини XVII в., а испанец Осел Хита Торрес, признанный Далай-ламой XIV - реинкарнацией ламы Еше Тубтена (1935-1984), известного на Западе тибетского монаха, основателя непальского монастыря Копан и международного Фонда поддержания традиции Махаяны.

Система реинкарнации - сложная модель для восприятия ее западными людьми, отрицающими эту концепцию в силу своей традиционной религиозной культуры и приверженности к современной материалистической науке.

Христиане отвергают доктрину перерождения, так как не находят в Библии ее подтверждения, поэтому перевоплощение обычно ограничивается раем или адом. Однако в раннем христианстве и позже, в период Средневековья, вера в повторные рождения сохранялась в разных видах. Ориген, один из наиболее влиятельных отцов церкви, веря в «предсуществование души», писал в III в.: «Некоторые души, склонные творить зло, попадают в человеческие тела, но затем, прожив отмеренный человеку срок, перемещаются в тела животных, а потом опускаются до растительного существования. Следуя обратным путем, они возвышаются и вновь обретают Царствие Небесное» [Origen 1966: 75]. Со временем христианство отвергло веру в реинкарнацию, хотя в эпоху Возрождения интерес христианского сообщества к идее переселения душ резко возрос. Большую роль в этом сыграл известный итальянский ученый и поэт Джордано Бруно. Из-за своих учений, в том числе и о реинкарнации, он был осужден судом инквизиции и сожжен на костре. В заключительном ответе на предъявленные ему обвинения Бруно заявил, что душа - «это не тело» и что «она может находиться как в одном, так и в другом теле и переходить из одного тела в другое» [Википедия].

Выдающиеся современные священнослужители и ученые, принадлежащие к различным направлениям христианства, признают возможность того, что ранние христиане склонялись скорее к теории перерождения, нежели к идее воскрешения и водворения в рай или ад. Лесли Уайтхед, современный священник методистской церкви и писатель, считает, что в христианских писаниях трудно найти прямые доказательства учения о переселении душ, но, несмотря на это, идея о перевоплощении души вполне совместима с учением Христа [Whitehead 1965: 296-297]. Как показывают данные социологических исследований, в настоящее время с каждым годом усиливается рост веры в реинкарнацию, исследователианалитики видят три его причины: 1) увеличивающийся интерес и уважение к восточной философии; 2) растущая озабоченность западной культуры явлением смерти; 3) признание значения новых методов терапии, основанных на опыте прошлых жизней [Geisler, Amano 1986: 26]. 
Научные исследования феномена реинкарнации начались в 1960-е гг. и с каждым десятилетием становятся все активнее. Главными методами исследований являются изучение воспоминаний детей о прошлых жизнях и использование регрессивного гипноза с целью добраться до глубинных слоев памяти, в которых, согласно теории, и содержатся воспоминания о прошлых воплощениях.

Масштабные исследования воспоминаний детей провел американский биохимик и профессор психиатрии Виргинского университета Ян Стивенсон, которым за 40 лет было изучено более 3000 случаев предполагаемой реинкарнации. По утверждениям автора, расследовались только случаи, когда воспоминания могли быть документально подтверждены, и во многих случаях ему удавалось найти доказательства, касающиеся прошлых жизней участников исследований: подтвердить имена родственников, описание места жительства и другие проверяемые подробности [Реинкарнация...].

Стивенсон выделил следующие доводы в пользу реальности перерождения: наличие большого числа случаев, когда люди, в основном дети младшего возраста, рассказывают о событиях, произошедших в прошлом с другими людьми; наличие у многих следов и отметин на теле, которые можно интерпретировать как своего рода «фантомные боли» от прошлых жизней; и комплекс таких факторов - маловероятность сговора между участниками воспоминаний, неизвестность сообщаемой информации для общественности, сочетание воспоминаний, отметин на теле и особых типов психоэмоционального состояния.

На феномен реинкарнации пролили некоторый свет исследования гипнотической памяти и другие работы в области психологии и психиатрии, проведенные в последние годы. Данный метод использовался как средство излечения таких нарушений деятельности организма, как фобии, судороги, избыточный вес, истерия и необъяснимые приступы боли. Иногда на сеансах гипноза выяснялось, что причина расстройства уходит корнями в более отдаленные времена, нежели детские годы пациента. По всей вероятности, источник симптомов исходил из прошлых жизней больного. Для излечения болезни нужно было с помощью гипноза вернуть пациента в его предыдущее воплощение, поскольку привычные методы лечения не давали осязаемых результатов. По мере того как психологи, занятые этими исследованиями, накапливали опыт общения с сотнями пациентов и информацию об их прошлых жизнях, они стали осознавать огромную важность явления, с которым столкнулись. В начале 1990-х гг. широкой публике были предложены десятки авторитетных книг на эту тему.

Приблизительно в то же время появилась информация о феномене околосмертного состояния. Речь идет о субъективных переживаниях людей, переживших клиническую смерть и открывших в себе существование некоей отдельной личности или души, которая может жить, находясь вне тела и сохранять воспоминания о его прошлой жизни. Впечатления тех, кто побывал в «пограничном состоянии», нередко совпадают с открытиями гипнотерапевтов, возвращавших своих пациентов в момент их смерти в прошлую жизнь, а затем к промежутку между смертью и новым рождением [Роузен 2002: 71].

Несмотря на все эти исследования, современная наука утверждает, что не существует ни одного достоверного научного подтверждения существования фе- 
номена реинкарнации, и считает, что вера в существование перерождения является одним из наиболее распространенных среди современных западных людей псевдонаучных заблуждений. Его Святейшество Далай-лама XIV сделал заявление: «Если ученые смогут доказать, что перерождения не существует, тогда буддистам придется отказаться от веры в его истинность, но если ученые не могут доказать, что эта теория ложна, тогда, поскольку они следуют логике и научному методу для понимания новых теорий и законов, они должны исследовать существование перерождения. Чтобы доказать, что перерождения не существует, они должны обнаружить его несуществование. Просто говорить: “Перерождения не существует, потому что я не вижу его своими глазами”, - не означает обнаружения несуществования перерождения. Есть много явлений, которые невозможно увидеть своими глазами, например магнетизм или силу тяжести. Научный метод состоит в том, чтобы сформулировать теорию, основанную на определенных данных, а затем проверить, можно ли считать эту теорию достоверной» [Берзин].

Буддийские ученые предпочитают термин «повторное рождение», а не «реинкарнация», поскольку они считают, что последний термин намекает на наличие «души», которая воплощается, и потому не подходит для буддизма. Большинство людей, говоря о «реинкарнации», понимают это так, будто есть «чтото», что вновь рождается и переходит из одной жизни в другую. Но в буддизме нет независимой и неизменной сущности, вроде души, которая переживала бы смерть тела. Буддисты считают, что непрерывность жизней обеспечивает не какая-то сущность, а наиболее тонкий уровень сознания.

В буддийских учениях приведено множество различных логических обоснований, доказывающих существование прошлых и будущих жизней. Вкратце все они сводятся к четырем логическим доводам: 1) каждому объекту и явлению предшествует объект и явление того же типа; 2) каждому объекту и явлению предшествует субстанциональная причина; 3) в прошлом ум уже обладал знанием об объектах и явлениях; 4) в прошлом у ума уже был опыт [взаимодействия] с объектами и явлениями. В конечном итоге все эти доводы опираются на мысль о том, что поскольку природа ума - это ясность и осознавание, то и субстанциональной причиной для ума должны быть ясность и осознавание. Посредством логического анализа устанавливается, что новый поток ясности и осознавания не может возникнуть без причин или из несоответствующих причин. Установив, что ум невозможно создать в лаборатории, делается вывод, что ничто не может положить конец тонкому [потоку] ясности и осознавания [Заявление...].

Существует два способа перерождения после смерти: перерождение в силу кармы и перерождение в силу сострадания и молитвы. В первом случае по причине неведения создается отрицательная и положительная карма, оставляющая отпечатки на сознании, что и приводит непроизвольно существо к новому рождению. Другими словами, перерождение обычных людей всецело определяется кармой и процессом созревания ее плодов, которое, в свою очередь, создает новую карму - и так до бесконечности. Как считают буддисты, «реинкарнация - 
это просто почтительный термин, применяемый для обозначения кармы» [Кхандро Ринпоче 2008: 145-146].

Существа, достигшие высокой ступени духовного развития (бодхисаттвы), перерождаются сознательно в силу сильного сострадания (бодхичитты) и молитвы. Бодхичитта - это мотивация, при которой ум, сердце и энергия полностью направлены на достижение состояния будды для помощи всем живым существам. Молитва здесь означает направление энергии человека определенным образом на то, чтобы в следующей жизни переродиться в такой форме, в такой ситуации, в такой семье и так далее, где будут все возможности для помощи другим. Эта система управления своими перерождениями очень сильно связана с буддийской практикой, в частности с практикой тантры, когда в процессе умирания обычно практикуется особый вид медитации.

В Тибете людей, которые имеют способность перерождаться осознанно, называют тулку. Этот термин, означающий «нирманакая, тело эманации, или явленное тело будды», употребляется в отношении распознанных воплощений ушедших лам и стал использоваться в качестве почетного звания. Нирманакая может быть трех видов: 1) высшее тело-нирманакая, его примером может быть Будда Шакьямуни, исторический будда; 2) творческое тело-нирманакая, с помощью которого будды служат другим, проявляясь как гении - люди, обладающие талантами или способностями, отличающиеся от обычных людей. К ним относятся выдающиеся художники, музыканты и т. д.; 3) воплощенное телонирманакая, с помощью которого будды проявляются в различных формах, например в образе людей, божеств, рек, мостов, целебных трав и деревьев, чтобы помогать другим существам. Воплощения духовных наставников, которые в Тибете распознаются и именуются «тулку», относятся к третьей из перечисленных категорий нирманакаи. Среди таких тулку, возможно, есть немало тех, кто полностью соответствует характеристикам воплощенного тела-нирманакаи будд, но это относится не ко всем. Среди тибетских тулку, возможно, есть и воплощения высших бодхисаттв на пути накопления и подготовки, а также наставников, которым по очевидным причинам еще только предстоит вступить на путь бодхисаттв. Таким образом, титул «тулку» присваивается воплощенным ламам либо на том основании, что они подобны просветленным существам, либо в силу их связи с определенными качествами просветленных существ [Заявление...].

Тибетцы называют тулку также ринпоче (драгоценность). В тибетской традиции это авторитетный духовный лидер тибетского буддизма, согласно традиционным воззрениям постоянно перерождающийся с целью продолжения своей духовной работы. Тибетская концепция перевоплощения сводится на данный момент к тому, что лама-учитель, умирая, в силу своей реализации и великого сострадания, перерождается вновь, чтобы вести своих учеников к Просветлению. Таким образом, среди распознанных в Тибете тулку есть монахи и практикующие тантру миряне, мужчины и женщины. Сегодня признанные тулку есть во всех основных традициях тибетского буддизма: в сакье, гелуг, кагью и ньингме. 
Система официального распознавания новых воплощений учителей возникла в начале XIII столетия, после получили развитие и распространение различные процедуры, связанные с ее практическим осуществлением. Наиболее важные из них предполагают рассмотрение пророческого письма предшественника и других оставленных им инструкций и указаний, где сообщались возможное место перерождения, а иногда и информация о будущих родителях. По истечении 49 дней после смерти духовного лидера в Тибете начинались поиски его перерождения, которые могли продолжаться от нескольких дней до нескольких лет. Поиски производились группой в составе лам-перерожденцев. В ходе поисков осуществлялся сбор информации о мальчиках, родившихся после смерти духовного лица, производились гадания, произносились молитвы, изучались пророчества и сны авторитетных лам, осмысливалась мистическая символика позы усопшего, проводилось наблюдение за водной гладью священных озер. На основании собранной информации определялось время и место рождения тулку. Поисковая группа выявляла одного или нескольких кандидатов. Мальчики подвергались испытанию: считалось, что перерожденцы могут вспомнить эпизоды или некоторые предметы из своей прошлой жизни, поэтому им давали множество предметов, среди которых помещалась невзрачная вещь, некогда принадлежавшая умершему. Выбор вещи ребенком служил весомым аргументом в пользу обнаружения тулку.

Институт тулку на протяжении многих столетий играл важную роль не только в собственно религиозной, но и в социально-политической жизни средневекового Тибета. В политическом аспекте он является альтернативой институту кровнородственного наследования и выборам при выдвижении политических и религиозных лидеров. Статус тулку давал его носителю авторитет и влияние, чем стремились воспользоваться самые разные силы: представители светской знати, мечтавшие, чтобы среди их детей был обнаружен перерожденец; цинский двор, пытавшийся решать политические вопросы посредством регулирования и контроля над поиском тулку, и мн. др. Другими словами, институт тулку был неразрывно связан с политическими интересами светских правителей и религиозных деятелей. В средневековом тибетском обществе эта система обеспечивала стабильность, снижение напряженности в борьбе за власть и непрерывность наращивания знаний в рамках буддийской традиции без прямой зависимости от родовых связей и краткосрочной политической ситуации.

Институт тулку не имеет аналогов в других культурах и сохранил свою актуальность вплоть до наших дней, несмотря на драматические события XX в. Одним из высших и наиболее популярных тулку сегодня является Далай-лама XIV, изначально считающийся воплощением Великого Бодхисаттвы Авалокитешвары (бодхисаттвы сострадания). Именно его деятельность после 1959 г. способствовала значительному росту интереса к тибетскому буддизму и интернационализации тибетского вопроса на Западе. Одна из функций Далай-ламы - признание и утверждение других тулку. Однако Далай-лама XIV неоднократно высказывался о будущем института тулку: «Образовательные реформы неизбежно приведут к 
реформированию многих средневековых религиозных институтов Тибета. Хорошо образованное население уже не будет верить в предсказания и тогда естественным образом снизится влияние тулку. Повсеместно распространенная буддийская система избрания глав монастырей посредством голосования, в конечном счете, вытеснит уникальную тибетскую систему избрания лидеров с помощью средневековых шаманских практик» [Сабиров]. О своем будущем перевоплощении он сказал, что когда ему исполнится 90 лет, он проконсультируется с высокими ламами тибетских буддийских традиций, тибетским народом и другими заинтересованными людьми из числа последователей тибетского буддизма, чтобы заново оценить, должен ли сохраниться институт далай-лам или нет. Если будет принято решение, что следует и далее искать реинкарнации далай-ламы, и есть необходимость в признании Далай-ламы XV, то ответственность за это преимущественно ляжет на определенных лиц доверительного фонда Далай-ламы «Гаден Пходранг». Они должны будут проконсультироваться с главами тибетских буддийских традиций и выполнить процедуры поиска и распознавания в соответствии с традицией прошлого. Им будут оставлены четкие инструкции в письменной форме. При этом он подчеркивает, что кроме признанной посредством таких легитимных методов кандидатуры, не может быть распознана и признана никакая другая, избранная по политическим соображениям кем бы то ни было [Там же].

Таким образом, сложность внедрения данной модели в практику буддизма на Западе заключается не в том, что метафизическая идея перевоплощения учителя в другом физическом теле находит когнитивное или эмоциональное неприятие. Западному адепту предстоит согласиться с тем, что авторитетный тибетский лама, его учитель, в своем следующем рождении может быть опознан в личности не только тибетца, но и западного человека. Не менее сложной для него станет необходимость выстраивать отношения ученика и учителя с маленьким ребенком, в котором признается перерождение его наставника. Безусловно, можно подвергнуть испытанию право и способность взрослого человека обучать Дхарме и на основе результатов испытания прийти к выводам о его соответствии духовным потребностям. Довольно трудно такого рода эксперименты применить к ребенку. Эта ситуация - относительно новое явление в процессе становления тибетского буддизма на Западе, потому что многие тибетские учителя, которые первыми принесли Дхарму на Запад, ушли из жизни за последние несколько лет и их перерождения только начинают опознавать. Выстраивание личных взаимоотношений западных учеников с этими маленькими ламами представляется все более важным элементом в создании и поддержании целостности, требуемой для выживания и дальнейшего успешного развития тибетского буддизма на Западе.

В большинстве случаев дети-перерожденцы не посещают западный континент в силу своего малого возраста или потому, что их религиозное обучение настолько интенсивно, что исключает возможность столь длительного путешествия. Многие из них живут в тибетских монастырях в Индии и Непале, где подчинены строгому режиму и инструкциям, неукоснительное исполнение которых составляет краеугольный камень инициации тулку и контролируется регентом 
или наставником, предварительно назначаемым покойным ламой, чье рождение признано в мальчике. В недалекой перспективе эти маленькие сейчас ламы вырастут в лидеров своих обществ, расположенных в западных странах. Изменения, которые станут возможными как следствие прихода тулку в организации, созданные предшественниками их рождений, представляют, наверное, самый волнующий для тибетского буддизма на Западе вопрос. Пока монашеские институты в Индии и Непале поддерживают свои обязательства по обучению и воспитанию новых тулку, можно ожидать, что правильность передачи доктрины и практики тибетского буддизма на Западе будет сохраняться и в дальнейшем.

Работа выполнена в рамках государственного задания «Трансформация направлений и школ буддизма: история и опыт взаимодействия с религиями и верованиями России, Центральной и Восточной Азии (с периода распространения буддизма до современности: Россия - XVIII-XXI вв.; Китай-II-XXI вв.; Тибет - VII-XXI вв.; Монголия - XVIXXI вв.)» № 121031000261-9.

\section{Питература}

Берзин А. Часто задаваемые вопросы о карме и перерождении [Электронный ресурс]. - Режим доступа: https://filosoff.org/buddhism/tvorchestvo/chasto-zadavaemye-voprosy-okarme-i-pererozhdenii-berzin-aleksandr/ (дата обращения: 22.11.2021).

Википедия [Электронный ресурс]. - Режим доступа: https://ru.wikipedia.org/wiki/ (дата обращения: 20.11.2021).

Заявление Его Святейшества Далай-ламы XIV, Тёнзина Гьяцо, касательно его нового воплощения [Электронный ресурс]. - Режим доступа: https://dalailama.ru/news/843zayavlenie-ego-svyatejshestva-dalaj-lamy-xiv-tenzina-gyaco-kasatelno-ego-novogo-voploshheniya.html (дата обращения: 18.11.2021).

Кхандро Ринпоче. Эта драгоценная жизнь. Учения тибетского буддизма о Пути к Просветлению / Кхандро Ринпоче. - М.: Открытый Мир, 2008. - 224 с.

Реинкарнация [Электронный ресурс]. - Режим доступа: https://dic.academic.ru/ dic.nsf/ruwiki/72123 (дата обращения: 22.11.2021).

Роузен С. Реинкарнация в мировых религиях / С. Роузен. - М.: Философская книга, 2002. - 152 c.

Сабиров Р. О будущем института тулку в тибетском буддизме [Электронный ресурс]. - Режим доступа: https://mongoloved.org/2014/12/19/tulku_future/ (дата обращения: 15.10. 2021).

Geisler N. L. The Reincarnation Sensation / N. L. Geisler, J. Y. Amano. - Weaton, 111: Tyndale House Publishers, 1986. - 186 p.

Lavine A. Tibatan Buddhism in America: The Development of American Vajrayana / A. Lavine // The Faces of Buddhism in America. - London: University of California Press, 1998. - P. 100-115.

Mackenzie V. Reincarnation: The Boy Lama / V. Mackenzie. - Bloomsbury; London, 1988. - 177 p.

Origen. On First Principles. Book 1, Chapter VIII / trans. W. W. Butterworth. - N. Y.: Harper \& Row, 1966.

Whitehead L. D. The Christian Agnostic / L. D. Whitehead. - Nashville: Abingdon Press, 1965. -304 p. 